\title{
MiniReview
}

\section{Unreduced gametes are the major causal factor for the production of polyploid interspecific hybrids in Primula}

\author{
Juntaro Kato ${ }^{1}$, Hiroaki Ohashi ${ }^{2}$, Mayuko Ikeda $^{3}$, Nobuyo Fujii ${ }^{1}$, Rieko Ishikawa ${ }^{1}$, \\ Haruhiko Horaguchi ${ }^{4}$, Junji Amano ${ }^{5}$, Mai Hayashi ${ }^{4}$, Masahiro Mii ${ }^{4}, *$ \\ ${ }^{1}$ Department of Biology, Aichi University of Education, 1 Kariya, Aichi 448-8542, Japan; ${ }^{2}$ Faculty of Agriculture, \\ Ehime University, Tarumi, Matsuyama, Ehime 790-8566, Japan; ${ }^{3}$ Graduate School of Bioagricultural Sciences, \\ Nagoya University, Aichi 470-0151, Japan; ${ }^{4}$ Graduate School of Horticulture, Chiba University, Matsudo, Chiba 271 - \\ 8510, Japan; ${ }^{5}$ Innovation Plaza Tokai, Japan Science and Technology Agency, 23-1 Nagoya, Aichi 457-0063, Japan \\ *E-mail: miim@faculty.chiba-u.jp Tel \& Fax: +81-47-308-8852
}

Received August 18, 2008; accepted November 5, 2008 (Edited by R. Ohsawa)

\begin{abstract}
The genus Primula (Primulaceae) consists of approximately 420 species that mainly inhabit temperate to cold regions of the Northern hemisphere. Although most species have attractive flowers with high ornamental value, few have been cultivated as ornamental plants. To develop novel ornamental crops and to introduce novel useful characters, these unexploited rich germplasms of the genus Primula have the potential to serve as breeding materials through the use of interspecific hybridization. However, interspecific hybrids of this genus have rarely been produced, and embryo rescue is one of the most useful strategies to overcome the difficulty of achieving successful hybridization, especially in wide crosses. In recent studies, we successfully obtained various interspecific hybrids in wide cross combinations in Primula using the embryo rescue technique, and showed that unexpected polyploid hybrids were frequently produced by the fertilization of unreduced female and/or male gametes, which were formed in most of the species examined. Some of the resultant hybrids have useful and attractive characters, and they have already been used directly as novel cultivars or incorporated into commercial breeding of novel types of primulas.
\end{abstract}

Key words: $\quad$ Embryo rescue, interspecific hybrid, polyploid, Primula, unreduced gamete.

Interspecific hybridization is an important strategy for plant breeding, but its success depends largely on the cross combination of species. For wide crosses, especially, the production of interspecific hybrids is difficult without the aid of embryo or ovule culture. In diploid interspecific hybrids obtained by wide crosses, most plants show hybrid sterility because of failure at meiosis. A commonly used method to overcome hybrid sterility, chromosome doubling of the hybrid to produce an amphidiploid, involves treating meristematic cells with mitotic inhibitors such as colchicine. In contrast, the spontaneous occurrence of unreduced gametes can produce unexpected polyploids such as triploids and tetraploids in both natural and artificial crosses in various plants such as Brassica (Mackay and Low 1975), Solanum (Johnston and Hanneman 1982), Lilium (Barbara-Gonzalez et al. 2004), Vaccinium (Dewit and Lyrene 1988) and Cyclamen (Takamura and Miyajima 1999). These polyploidized hybrids may be used directly for further breeding because of the full or partial restoration of their fertility.

The genus Primula (Primulaceae) consists of approximately 420 species that are classified into 37 sections based on morphological characters (Richards 1993). Most Primula species have attractive flowers with high ornamental value, and some, such as $P$. malacoides Franch., P. obconica Hance and P. sieboldii Morr., have been cultivated for many years as important ornamental plants. Although several interspecific hybrids such as P. $\times$ polyantha and P. $\times$ kewensis have also been used as ornamental plants, most have been produced by crosses between species belonging to the same section, without applying embryo rescue treatments such as ovule culture.

In this review, we summarize our recent studies on wide hybridization, such as inter-sectional and intersubsectional hybridizations, in the genus Primula. Since hybrids with unexpected ploidy levels arose with high frequency during these studies, we discuss unreduced gamete formation as a possible mechanism involved in this phenomenon and its significance for successful interspecific hybridization.

\section{Polyploidized interspecific hybrid in the subgenus Auganthus of Primula}

Many species within the subgenus Auganthus of Primula 
are distributed throughout China, Korea, Siberia and Japan but only a few, such as $P$. obconica and $P$. sinensis, have been developed as cultivated plants. In Japan, Primula sieboldii E. Morr., is one of the species in this subgenus that is traditionally cultivated as an ornamental plant, and over 300 cultivars have been produced and conserved by vegetative propagation since about 300 years ago. To produce novel cultivars, we performed interspecific hybridization in the subgenus Auganthus, mainly using cultivars of $P$. sieboldii as one parent.

\section{P. sieboldii $\times$ P. kisoana}

Both Primula sieboldii and $P$. kisoana are native to Japan and are classified in the section Cortusoides. P. sieboldii (subsection Cortusoides) ranges widely from Kyusyu to Hokkaido but in localized areas, whereas P. kisoana (subsection Geranioides) is restricted to narrow areas of Shikoku and Kanto. When these two species were crossed, mature seeds were obtained but most failed to germinate on the soil even when they were treated with $100 \mathrm{mg} \mathrm{l}^{-1}$ gibberellic acid $\left(\mathrm{GA}_{3}\right)$. The few seeds that did germinate died at the cotyledonary stage. We therefore conducted immature seed culture four weeks after interspecific crossing on $0.3 \%$ gellan gum-solidified half-strength MS medium (Murashige and Skoog 1962) (1/2 MS) supplemented with $5 \%(\mathrm{w} / \mathrm{v})$ sucrose and 50 $\mathrm{mg}^{-1} \mathrm{GA}_{3}$ (Kato and Mii 2000). From a total of 34 cross combinations, using 14 cultivars of $P$. sieboldii and three of P. kisoana, we obtained interspecific hybrid plants from seven out of nine reciprocal cross combinations. The interspecific hybrids thus obtained showed two different ploidy levels depending on the species used as maternal parent. When P. sieboldii was the maternal parent, only two cultivars, Miyuki and Ooasahi, produced hybrids, which had triploid DNA content, whereas reverse cross combination using the strain 'Shirobana-Shikoku' of $P$. kisoana as the maternal parent yielded normal diploid hybrids (Table 1). Since the triploid hybrids possessed one large satellite chromosome specific to P. kisoana and two small ones specific to $P$. sieboldii, we concluded that they were produced by the fertilization of an unreduced female gamete of $P$. sieboldii by a normally reduced male gamete of $P$. kisoana (unpublished result). There are two possible reasons for the difference in ploidy level of these hybrids, depending on the direction of cross combination: (1) zygotic hybrid embryos produced by the fertilization of unreduced female gametes of $P$. sieboldii could only develop in the ovule of $P$. sieboldii, and (2) unreduced female gametes were selectively fertilized in this interspecific cross combination. Further studies are needed to clarify the mechanism involved in the difference in ploidy level among the progenies obtained in these reciprocal crosses.

\section{P. sieboldii $\times P$. obconica}

$P$. obconica, which is classified in the section Obconicolisteri, is one of the most important Primula species to be cultivated as a horticultural plant. In $P$. obconica, there have been no reports of interspecific hybridization except for one study on somatic hybridization with $P$. malacoides through protoplast fusion (Mizuhiro et al. 2003). We therefore carried out interspecific crossing between $P$. sieboldii and $P$. obconica, which is an intersectional wide cross. Three to four weeks after crossing, embryo rescue culture was performed on $0.25 \%(\mathrm{w} / \mathrm{v})$ gellan gum-solidified $1 / 2 \mathrm{MS}$ supplemented with $5 \%$ sucrose, $20 \mathrm{mg}^{-1} \mathrm{GA} 3,0.1 \mathrm{mg}$ $1^{-1} 1$-naphthaleneacetic acid (NAA) and $0.1 \mathrm{mgl}^{-1}$ 6benzylaminopurine (BA). Among 140 reciprocal crosses using 54 cultivars of $P$. sieboldii and eight of $P$. obconica, we obtained 15 plants, all of which were from nine crosses using $P$. sieboldii as the maternal parent (Kato et al. 2001). Because a 2.5 -fold difference in DNA content was found between $P$. sieboldii (SS genome) and $P$. obconica (OO genome), we estimated the hybridity as well as genomic composition of the plants obtained from this interspecific cross by flow cytometric analysis. Two types of ploidy level with three genomic compositions were found: 10 diploids (SO genome), four triploids with two genomes of $P$. sieboldii and one of P. obconica (SSO genome), and one triploid with the reverse composition (SOO genome). The high rate (33\%) of triploid hybrid formation suggests that unreduced gametes produced from both parents contributed frequently to the formation of hybrids in this interspecific cross combination. Among the four SSO hybrids, one was produced from 'Miyuki', which has been reported to form unreduced gametes (Kato and Mii 2000), but the other three arose from crosses involving other cultivars which, when used as the female parent, did not produce hybrids in crosses with P. kisoana. These results suggest that unreduced gamete formation occurs in different genotypes of $P$. sieboldii, and that successful production of interspecific hybrids may be affected by the genotypes of both parents used for each interspecific cross combination. In $P$. sieboldii, several triploid cultivars were found, and giant pollen has also been observed in this species (Yamaguchi 1973). These triploid cultivars may therefore have arisen from fertilizations with unreduced gametes produced on either the male or the female side of this species. However, the frequency of unreduced gamete formation in P. sieboldii is likely to be quite low, since triploids were produced at a low frequency $(3.5 \%)$ and only in restricted parental combinations in intraspecific crosses involving this species (Table 1). Since an SOO genome hybrid was produced in the cross where $P$. sieboldii was the female parent, $P$. obconica also has the ability to produce unreduced male gametes, which here contributed to the 
Table 1. Ploidy level of progenies in interspecific crosses between P. sieboldii and P. kisoana and intraspecific crosses of $P$. sieboldii determined by flow cytometric analysis

\begin{tabular}{|c|c|c|c|c|c|}
\hline \multirow{2}{*}{ Cross } & & \multirow{2}{*}{$\begin{array}{c}\text { No. of } \\
\text { progenies }\end{array}$} & \multicolumn{3}{|c|}{ Ploidy level } \\
\hline & & & diploid & triploid & tetraploid \\
\hline \multicolumn{6}{|c|}{ P. sieboldii / P. kisoana } \\
\hline Miyuki & Iyobeni & 42 & $1^{\text {a) }}$ & 41 & 0 \\
\hline Miyuki & Shirobana-Shikoku & 11 & 0 & 11 & 0 \\
\hline Ooasahi & Shikoku W1 & 2 & 0 & 2 & 0 \\
\hline Kourohou & Shikoku W1 & 3 & $3^{\text {a) }}$ & 0 & 0 \\
\hline Mihonokoji & Iyobeni & 4 & $4^{\text {a) }}$ & 0 & 0 \\
\hline \multicolumn{6}{|c|}{ P. kisoana / P. sieboldii } \\
\hline Shirobana-Shikoku & Ooasahi & 12 & 12 & 0 & 0 \\
\hline Shirobana-Shikoku & Youdainoyume & 18 & 18 & 0 & 0 \\
\hline Shirobana-Shikoku & Tagonoura & 3 & 3 & 0 & 0 \\
\hline Shirobana-Shikoku & Hinotsukasa & 2 & 2 & 0 & 0 \\
\hline \multicolumn{6}{|c|}{ Intraspecific crosses of $P$. sieboldii } \\
\hline Miyuki & Gifu & 11 & $11(100 \%)$ & 0 & 0 \\
\hline Miyuki & Shiro-tonbo & 86 & $82(95.3 \%)$ & $3(3.5 \%)$ & $1(1.2 \%)$ \\
\hline Miyuki & Chidori-asobi & 2 & $2(100 \%)$ & 0 & 0 \\
\hline Miyuki & Tsukumo-jishi & 3 & $3(100 \%)$ & 0 & 0 \\
\hline Ooasahi & Chidori-asobi & 16 & $16(100 \%)$ & 0 & 0 \\
\hline Kotobuki & Shiro-tonbo & 5 & $5(100 \%)$ & 0 & 0 \\
\hline
\end{tabular}

${ }^{a}$ No evidence of hybridity in interspecific hybridization by RAPD analysis

production of triploid hybrids.

\section{P. filchnerae $\times P$. sinensis}

Polyploidized hybrids were also obtained in another intersectional combination, i.e., between $P$. filchnerae $(2 \mathrm{n}=2 \mathrm{x}=24)$ and $P$. sinensis $(2 \mathrm{n}=2 \mathrm{x}=24)$, in the subgenus Auganthus. P. sinensis (section Auganthus), a perennial species native to China, has been improved as an ornamental plant in Europe since around 1800. Although it has acquired many mutations during its long cultivation history (Richards 1993), interspecific hybrids using this species have not been reported. On the other hand, P. filchnerae, an annual species belonging to the section Pinnatae, is also native to China and has recently become popular as a novel ornamental crop in Japan. Because this species has the characteristics of producing several flower stalks with many flowers and of blooming continuously from late February to early May, it would be desirable to introduce these advantageous characters into other species.

From a total of 26 reciprocal cross combinations made in this intersectional cross combination, only three seeds successfully germinated under the same ovule culture conditions used for the cross between $P$. sieboldii and $P$. obconica, in which the concentration of $\mathrm{GA}_{3}$ was increased from 20 to $50 \mathrm{mgl}^{-1}$. However, all three produced only radicles with calli and then stopped growing (Figure 1A). Two of these abnormal seedlings regenerated shoots after they were transferred onto $1 / 2$ MS supplemented with $30 \mathrm{gl}^{-1}$ sucrose, $3 \mathrm{gl}^{-1}$ gellan gum, $0.1 \mathrm{mg}^{-1} \mathrm{NAA}$ and $1 \mathrm{mg}^{-1}$ zeatin (Figure 1B).

Since a 1.2-fold difference in DNA content was found between $P$. filchenrae (FF genome) and $P$. sinensis (AA genome), hybridity, ploidy level and genome composition were estimated for the two regenerated plants (Amano et al. 2006). One of them, obtained from a cross using $P$. filchenrae as the female parent, showed a diploid DNA content (FA genome) intermediate between both species. In contrast, the DNA content of the remaining plant, from a cross using $P$. sinensis as the female parent, was comparable to the value expected for a hexaploid with four genomes of $P$. filchnerae and two of $P$. sinensis (FFFFAA genome); this was confirmed by counting the chromosome number in somatic cells (Figure 1C-F). The hexaploid plant probably arose from spontaneous genome duplication of a triploid interspecific hybrid, formed by the fertilization by an unreduced male gamete produced by $P$. filchnerae of a reduced egg of $P$. sinensis, although the presence of unreduced pollen has not yet been confirmed microscopically. Chromosome doubling might also have occurred during plant regeneration from the abnormal radicle tissue in vitro, since diploid interspecific hybrids obtained in the opposite cross direction are also easily duplicated into tetraploids during micropropagation in vitro (unpublished data). Since diploids, triploids and tetraploids have been reported in cultivars of $P$. sinensis (Richards 1993), it is reasonable to consider that both $P$. sinensis and $P$. filchnerae have the capacity to induce spontaneous meiotic and/or mitotic duplications frequently. 

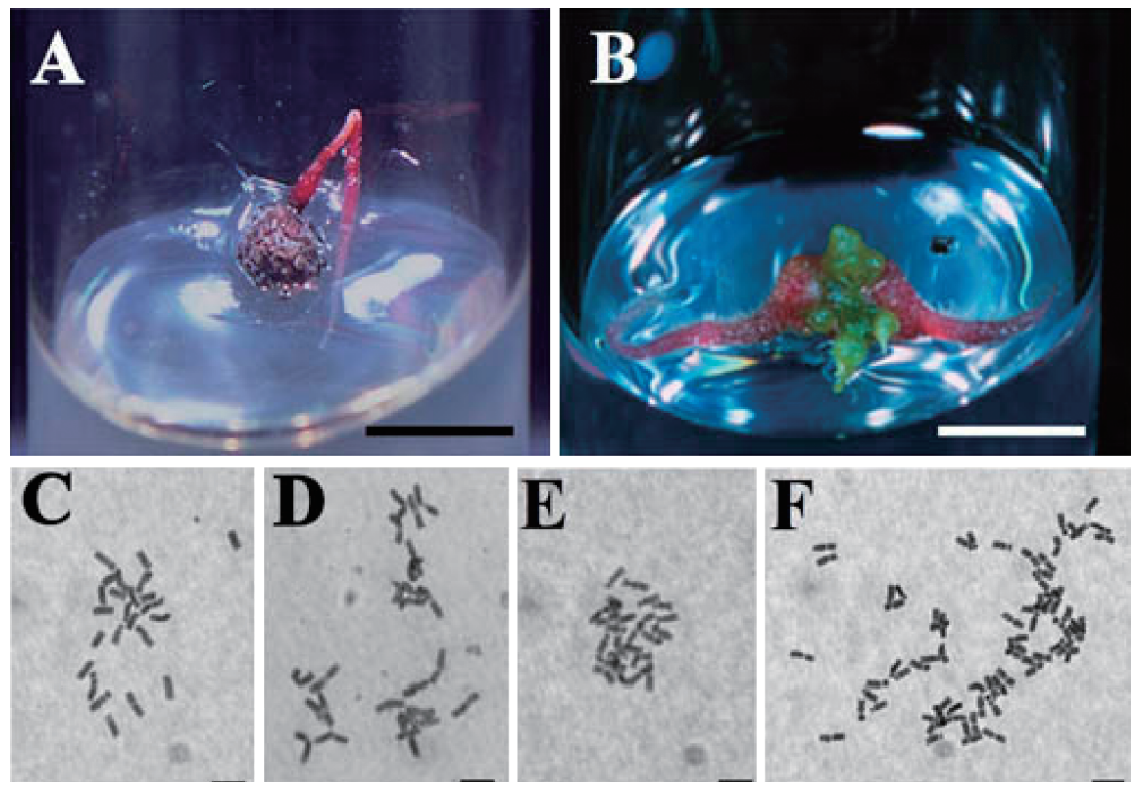

Figure 1. Plant regeneration from abnormal seedling (A, B) and somatic chromosomes (C-F) in interspecific hybridization between Primula filchnerae and P. sinensis. (A) Arrested seed germination on the embryo rescue medium. (B) Shoot regeneration from the radicle of an abnormal seedling on medium supplemented with $0.1 \mathrm{mg}^{-1}$ NAA and $1 \mathrm{mg} \mathrm{l}^{-1}$ zeatin. (C) P. filchnerae $(2 \mathrm{n}=2 \mathrm{x}=24)$, (D) P. sinensis $(2 \mathrm{n}=2 \mathrm{x}=24)$, (E) diploid hybrid $(2 \mathrm{n}=2 \mathrm{x}=24)$, (F) hexaploid hybrid $(2 \mathrm{n}=6 \mathrm{x}=72)$. Bars $=1 \mathrm{~cm}$ for $\mathrm{A}$ and $\mathrm{B}$, and $5 \mu \mathrm{m}$ for $\mathrm{C}-\mathrm{F}$.

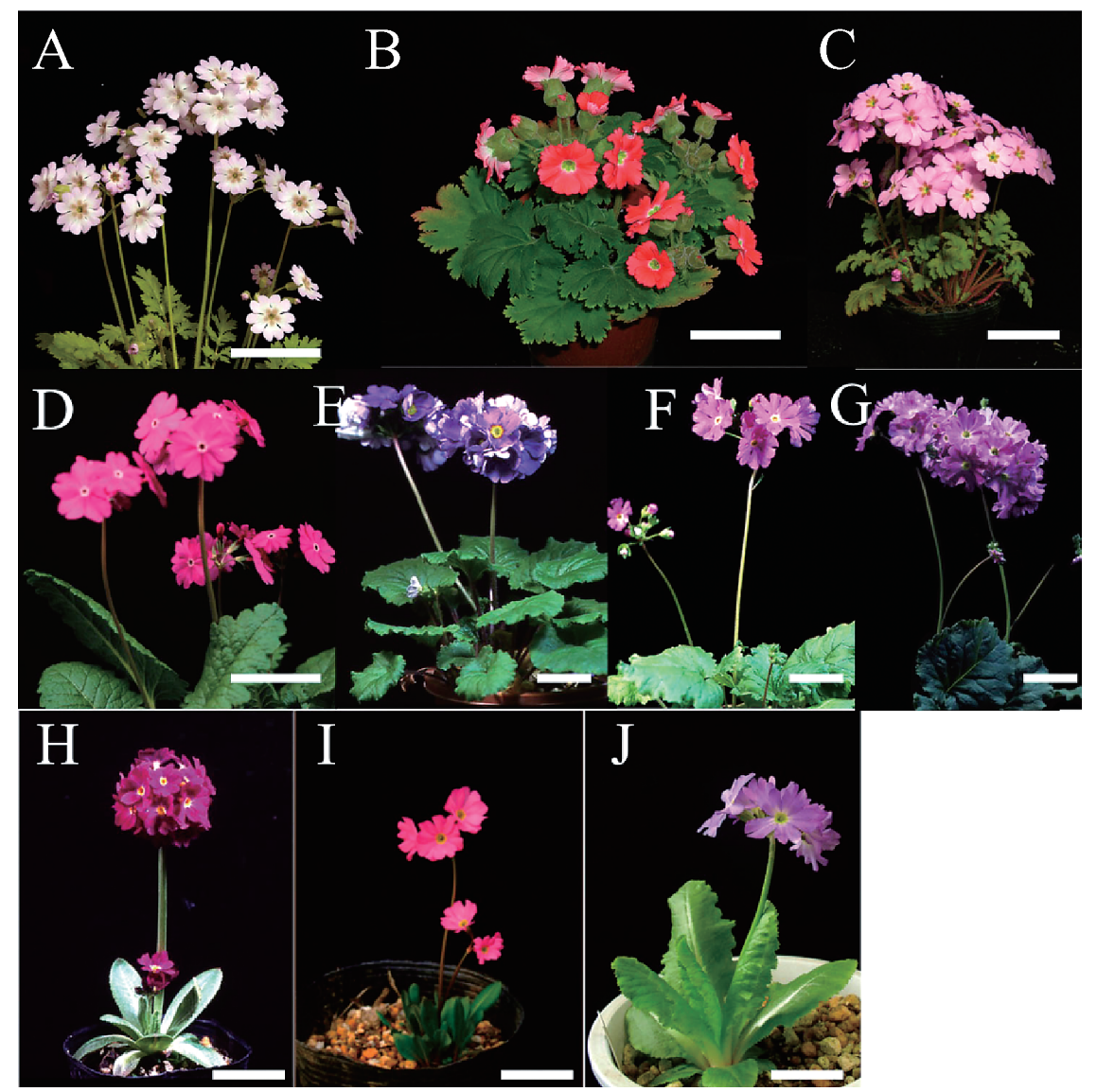

Figure 2. Parental species and their interspecific hybrids in Primula. (A) P. filchnerae (section Pinnatae), (B) P. sinensis (section Auganthus), (C) diploid interspecific hybrid between $P$. filchnerae and $P$. sinensis, which has been commercialized as 'Primula 31', (D) $P$. sieboldii (section Cortusoides), (E) P. obconica (section Obconicolisteri), (F) diploid hybrid between P. sieboldii and P. obconica, (G) triploid hybrid with SOO genome between P. sieboldii and P. obconica, (H) P. denticulata (section Denticulata), (I) P. rosea (section Oreophlomis), (J) Interspecific hybrid between $P$. denticulata and $P$. rosea. Bars $=5 \mathrm{~cm}$. 


\section{Polyploidized interspecific hybrids in the subgenus Aleuritia of Primula}

\section{$P$. denticulata $\times P$. rosea}

Polyploidized progenies were also obtained in interspecific hybridization between $P$. denticulata and $P$. rosea, both of which belong to the subgenus Aleuritia. $P$. denticulata is native to the Himalayan region, classified in the section Denticulata, and cultivated as an ornamental plant due to its beautiful flowers (with varied colors such as pink, white and purple) gathering on a unique bowl-like inflorescence resembling that of Allium. In our study, tetraploid cultivars were used because commercially available cultivars in Japan are only tetraploids $(2 \mathrm{n}=4 \mathrm{x}=44)$. On the other hand, P. rosea is also native to the Himalayas but is classified in the section Oreophlomis. To introduce the unique flower color of salmon pink, this species was crossed with tetraploid $P$. denticulata. Among the total of 35 cross combinations made with 64 pollinations, $P$. denticulata was used as the maternal parent in five cross combinations (28 pollinations), and P. rosea in 30 cross combinations (36 pollinations) (Hayashi et al. 2007a). Ovule culture was performed about four weeks after pollination, using the same medium as for the cross of $P$. filchnerae and P. sinensis. Seedlings that germinated normally with four or five true leaves were transferred into medium lacking plant growth regulators.

Hybridity of plants obtained from the interspecific reciprocal crossing between tetraploid $P$. denticulata $(2 \mathrm{n}=4 \mathrm{x}=44 ;$ DDDD genome) and diploid $P$. rosea $(2 \mathrm{n}=2 \mathrm{x}=22$; RR genome) could be confirmed by flow cytometry because the DNA content of tetraploid $P$. denticulata is 1.6 -fold higher than that of diploid $P$. rosea. A total of 318 plants were obtained by crosses using tetraploid $P$. denticulata as the female parent, and all of them were triploid hybrids as expected. In contrast, 22 of 71 plants obtained by crosses using two strains of $P$. rosea as the female parent showed hybridity, whereas the remainder were maternal-type diploids. Among the 22 hybrids, five were triploids (DDR genome) as expected, but the other 17 were tetraploids (DDRR genome) produced by the fertilization of unreduced female gametes of $P$. rosea. These results suggest that unreduced gamete formation may also be a common phenomenon in the subgenus Aleuritia.

\section{P. denticulata $\times P$. modesta}

To produce further variations of $P$. denticulata $(2 \mathrm{n}=$ $4 \mathrm{x}=44$ ), we also conducted interspecific hybridization with $P$. modesta (section Aleuritia), which is native to alpine regions of Japan and has three varieties in addition to the fundamental species. Flow cytometry and chromosome observation revealed that $P$. modesta var. matsumurae, which mainly inhabits Rebun Island, is tetraploid $(2 n=4 x=36)$, whereas all the other taxa of this species are diploids $(2 \mathrm{n}=2 \mathrm{x}=18)$. Interspecific reciprocal crosses were performed between each of the three varieties of $P$. modesta and tetraploid $P$. denticulata by the same method used for $P$. filchnerae $\times P$. sinensis. In reciprocal crosses between tetraploid $P$. denticulata $(2 \mathrm{n}=4 \mathrm{x}=44)$ and two diploid taxa $(2 \mathrm{n}=2 \mathrm{x}=18)$ of $P$. modesta, i.e., var. fauriae and var. samanimontana, and in the reciprocal tetraploid crosses between $P$. denticulata and P. modesta var. matsumurae, a total of 202 and 40 cross combinations were performed, respectively (Hayashi et al. 2007b). In the diploid-tetraploid crosses, the germination rates in crosses using a tetraploid as the female parent were considerably higher than those using a diploid as the female parent. In crosses between tetraploid female and diploid male parents, triploid hybrids were mainly obtained, as expected, but some polyploid hybrids (including tetraploids caused by fertilization with unreduced male gametes from diploids, pentaploids arising from unreduced female gametes from tetraploids, and hexaploids) were also obtained. In the reverse crosses, five of 11 were unexpectedly tetraploid, caused by fertilization with unreduced female gametes from diploids, three were triploid as expected, and three were hexaploid. Hexaploids produced in these reciprocal crosses were presumably formed by somatic duplication of triploid hybrids during embryogenesis or the early stage of seedling growth.

In the tetraploid crosses between $P$. denticulata and $P$. modesta var. matsumurae, both reciprocal cross combinations mainly produced tetraploids, with two kinds of unexpected hexaploids formed by fertilization with unreduced gametes of either parent, and octaploids were also detected by flow cytometric and somatic chromosomal observations.

In these interspecific crosses we obtained, in addition to the expected triploid and tetraploid hybrids, four kinds of unexpected polyploidized hybrids, including pentaploids, two kinds of hexaploid with two genomic constitutions, and octaploids. These results suggest that not only unreduced gamete formation but also somatic chromosome doubling may be causal factors for producing polyploidized hybrids in such interspecific crosses.

Significance of unreduced gametes and mitotic chromosome doubling for breeding in Primula

Interspecific hybridization and polyploidization are important tools for producing novel cultivars. Some ornamental primulas, such as polyantha (P.×polyantha) and auricula (interspecific hybrids using $P$. auricula and related species), originated from multiple interspecific crosses without embryo rescue, and numerous cultivars have been produced in these primulas at diploid level without serious problems. However, it is difficult to 
Table 2. Ploidy level of progeny plants and identification of the donor of unreduced gamete for inducing unexpected ploidy plants in interspecific hybridization in Primula

\begin{tabular}{|c|c|c|c|c|}
\hline Cross combination $(q / ठ)$ & $\begin{array}{c}\text { Number of hybrids } \\
\text { obtained }\end{array}$ & Ploidy level of progeny & & $\begin{array}{c}\text { Donor of unreduced } \\
\text { gamete unexpected } \\
\text { ploidy }\end{array}$ \\
\hline & & diploid & triploid & \\
\hline P. sieboldii / P. kisoana & 54 & 0 & 54 & unclear \\
\hline P. kisoana / P. sieboldii & 35 & 35 & & \\
\hline P. sieboldii / P. obconica & 15 & 10 & 5 & mostly female \\
\hline P. obconica / P. sieboldii & 0 & & & \\
\hline P. filchnerae / P sinensis & 1 & 1 & & \\
\hline P. sinensis / P. filchnerae & 1 & $1(1)^{\mathrm{a}}$ & male & \\
\hline diploid / tetraploid or tetraploid / diploid & & triploid & tetraploid or pentaploid & \\
\hline P. denticulata / P. rosea & 318 & 318 & & \\
\hline P. rosea / P. denticulata & 22 & 5 & 17 & only female \\
\hline P. denticulata / diploid P. modesta & 1053 & $1034(18)^{\mathrm{a}}$ & 19 & mostly male \\
\hline diploid P. modesta / P. denticulata & 11 & $6(3)^{a}$ & 5 & only female \\
\hline tetraploid / tetraploid & & tetraploid & hexaploid & \\
\hline P. denticulata / tetraploid P. modesta & 545 & $539(1)^{\mathrm{a}}$ & 6 & mostly female \\
\hline tetraploid P. modesta / P. denticulata & 304 & $303(2)^{\mathrm{a}}$ & 1 & male \\
\hline
\end{tabular}

${ }^{a}$ Number in parenthesis indicates the number of hybrid plants that showed spontaneous chromosome doubling when the ploidy level was checked at the young seedling stage.

achieve fertility in most of the interspecific hybrids obtained by wide crosses, as shown in our study of Primula. For such sterile interspecific hybrids to be useful, it is necessary to restore fertility, for the production of amphidiploids, by artificial chromosome doubling with the use of mitotic inhibitors such as colchicine. In some interspecific hybrids, spontaneous chromosome doubling sometimes occurs (Haga 1954, Nimura et al. 2006). In the genus Primula, $P$. $\times$ kewensis, an interspecific hybrid between $P$. verticillata and $P$. floribunda, is an example of a naturally produced amphidiploid in which fertility is known to have been restored after chromosome doubling (Richards 1993). Such mitotic chromosome doubling was also observed in hybrids between $P$. filchnerae and $P$. sinensis, and between $P$. rosea and P. modesta, as shown in our studies. These results suggest that spontaneous chromosome doubling may occur more frequently in interspecific hybrids than in the parental species, probably due to the instability of mitotic division in hybrid meristematic cells.

In all cross combinations tested in the present study, interspecific hybrids with unexpected ploidy levels arose predominantly from the fertilization of unreduced gametes produced by either one or both parental species (Table 2). In crosses between diploid and tetraploid $P$. malacoides, formation of predominantly tetraploid progenies was also reported (Skiebe 1958). Therefore, it is likely that unreduced gamete formation is a general phenomenon in the genus Primula. The frequency of unexpected polyploidy formation in Primula was clearly affected by the genotype of either one or both parents, as shown in Table 1. A genotypic effect on the frequency of unexpected polyploidy formation has also been reported in other genera such as Brassica (Mackay and Low 1975), Vaccinium (Dweikat and Lyrene 1988, Ortiz et al. 1992) and Cyclamen (Takamura and Miyajima 1999), suggesting that unreduced gamete formation is a genetically controlled trait. In potato, unreduced gamete formation is known to be regulated by the sy allele, and recessive homozygous $s y$ genotypes show unreduced egg formation (Iwanaga and Peloquin 1979). In the genus Primula, however, it is difficult to clarify the mechanisms involved in unreduced gamete formation because the frequency of unreduced gamete formation appears to be low, as shown in P. sieboldii (Table 1). For the utilization of unreduced gametes in polyploid breeding, it will be necessary to produce strains that have a high frequency of unreduced gamete formation, and to clarify the mechanisms involved in this unique and important phenomenon.

Since it is extremely rare to find polyploid progenies in intra-specific crosses between the species used in the present study, the frequency of unreduced gamete formation is also likely to be extremely low. Therefore, understanding the mechanisms involved in the selective formation or survival of zygotic hybrid embryos, which are produced by the fertilization of unreduced gametes, is an important goal of future research.

As described above, unreduced gametes could be used to efficiently produce triploid hybrids in crosses between diploid species. Although diploid interspecific hybrids obtained by wide cross are usually sterile, triploid hybrids obtained in the present study (such as the DDR hybrid produced by crossing tetraploid $P$. denticulata with diploid $P$. rosea, and the SOO hybrid produced by 
the cross between $P$. sieboldii and unreduced pollen of $P$. obconica) showed some fertility. Since such triploid hybrids are useful for transferring desirable characters from one species to another (Shigyo et al. 1996), they were subjected to backcrossing with one of the parental species. Consequently, the SOO triploid hybrid successfully yielded aneuploids after backcrossing twice with $P$. obconica (unpublished data). These aneuploids will eventually be used to produce $P$. obconica having useful traits of $P$. sieboldii, such as disease resistance and various flower morphologies. In contrast, backcrossing of the DDR triploid hybrid using pollen of tetraploid $P$. denticulata yielded mainly near or true pentaploids, due to unreduced female gamete formation in the triploid hybrid. Therefore, it is possible that this triploid interspecific hybrid has the ability to produce unreduced gametes at high frequency.

In the section Aleuritia, which includes $P$. modesta, at least five different ploidy levels are recognized, and species found at high latitudes above $40^{\circ} \mathrm{N}$ are mostly polyploid (Guggisberg et al. 2006). It is likely that unreduced gamete formation has played an important role in the evolution of such polyploid species in this section. The unreduced gamete formation commonly observed in the genus Primula is thus an interesting phenomenon from both breeding and evolutional viewpoints.

\section{Conclusion}

As shown above, embryo rescue using the ovule culture method and appropriate culture media has successfully yielded various types of interspecific hybrids in the genus Primula (Figure 2). Although interspecific hybrids are usually used as breeding materials, the hybrid between $P$. filchnerae and $P$. sinensis obtained in our study has been commercialized directly under the cultivar name of 'Primula 31' because of its novel, unique and high ornamental value. Further breeding of this hybrid is now in progress, using the fertile amphidiploid which was produced by spontaneous chromosome doubling during in vitro propagation. These results are a successful example of how interspecific hybridization can be an effective strategy for breeding ornamental plants, and suggest the usefulness of embryo rescue technology as a tool to overcome the difficulty of achieving hybrid production. Embryo rescue technology is now being tested for other combinations of species in the genus Primula, as well as for other ornamental crops.

\section{References}

Amano J, Kato J, Nakano M, Mii M (2006) Production of intersection hybrids between Primula filchnerae and P. sinensis through ovule culture. Sci Hort 110: 223-227
Barbara-Gonzalez R, Lokker AC, Lim KB, Ramanna MS, Van Tuyl JM (2004) Use of $2 n$ gametes for the production of sexual polyploids from sterile Oriental $\times$ Asiatic hybrids of lilies (Lilium). Theor Appl Genet 109: 1125-1132

Dweikat IM, Lyrene PM (1988) Production and viability of unreduced gametes in triploid interspecific blueberry hybrids. Theor Appl Genet 76: 555-559

Guggisberg A, Mansion G, Kelso S, Conti E (2006) Evolution of biogeographic patterns, ploidy levels, and breeding systems in a diploid-polyploid species complex of Primula. New Phytol 171: 617-632

Haga T (1954) Genome and polyploidy in the genus Trillium. Japan J Genet 29: 228-234 (in Japanese)

Hayashi M, Kato J, Ohashi H, Mii M (2007a) Variation of ploidy level in inter-section hybrids obtained by reciprocal crosses between tetraploid Primula denticulata $(2 \mathrm{n}=4 \mathrm{x}=44)$ and diploid P. rosea $(2 \mathrm{n}=2 \mathrm{x}=22)$. J Hort Sci Biotechnol 82: 5-10

Hayashi M, Kato J, Ichikawa Y, Matsubara N, Ohashi H, Mii M (2007b) Inter-sectional hybrids with various ploidy levels between Primula denticulata and three varieties of $P$. modesta. Breed Sci 57: 165-173

Iwanaga M, Peloquin SJ (1979) Synaptic mutant affecting only megasporogenesis in potatoes. J Heredity 70: 385-389

Johnston SA, Hanneman RE Jr (1982) Manipulations of endosperm balance number overcome crossing barrier between diploid Solanum species. Science 217: 446-448

Kato J, Mii M (2000) Differences of ploidy levels in interspecific hybrids between Primula sieboldii and P. kisoana. Theor Appl Genet 101: 690-696

Kato J, Ishikawa R, Mii M (2001) Different genomic combinations in inter-section hybrids obtained from the crosses between Primula sieboldii (Section Cortusoides) and P. obconica (Section Obconicolisteri) by the embryo rescue technique. Theor Appl Genet 102: 1129-1135

Lim KB, Ramanna MS, Jacobsen E, van Tuyl JM (2003) Evaluation of $\mathrm{BC} 2$ progenies derived from $3 \mathrm{x}-2 \mathrm{x}$ and $3 \mathrm{x}-4 \mathrm{x}$ crosses of Lilium hybrids: a GISH analysis. Theor Appl Genet 106: 568-574

Mizuhiro M, Ito K, Mii M (2001) Production and characterization of interspecific somatic hybrids between Primula malacoides and P. obconica. Plant Sci 161: 489-496

Mackay GR, Low RJ (1975) Spontaneous triploids in forage kale, Brassica oleracea var. acephala. Euphytica 24: 525-529

Murashige T, Skoog F (1962) A revised medium for rapid growth and bioassay with tobacco tissue cultures. Physiol Plant 15: 473-497

Nimura M, Kato J, Mii M, Katoh T (2006) Amphidiploids produced by natural chromosome-doubling in interspecific hybrids between Dianthus $\times$ isensis Hirahata et Kitamura and $D$. japonicus Thunb. J Hort Sci Biotechnol 81: 72-77

Ortiz R, Bruederle LP, Laverty T, Vorsa N (1992) The origin of polyploids via $2 \mathrm{n}$ gametes in Vaccinium section Cyanococcus. Euphytica 61: 241-246

Richards J (1993) Primula. Timber Press, Portland, Oregon, USA

Skiebe K (1958) Die Bedeutung von unreduzierten Gameten für die Polyploidiezüchtung bei der Fliederprimel Primula malacoides. Züchter 28: 353-359

Shigyo M, Tashiro Y, Isshiki S, Miyazaki S (1996) Establishment of a series of alien monosomic addition lines of Japanese bunching onion (Allium fistulosum L.) with extra chromosomes from shallot (A. cepa L. Aggregatum group). Genes Genet Syst 71: $363-371$ 
Takamura T, Miyajima I (1999) Varietal and individual differences in cross-compatibility in the crosses of cyclamen (Cyclamen persicum Mill.). J Japan Soc Hort Sci 68: 55-60
Yamaguchi S (1973) Cytogenetical studies in Primula sieboldii E. MORREN-Chromosome numbers of 80 cultivars and related species. Japan J Breed 23: 86-92 